\title{
Spatial distribution and cluster analysis of a leishmaniasis outbreak in the south-western Madrid region, Spain, September 2009 to April 2013
}

\author{
D Gomez-Barroso ${ }^{1,2,3}$, Z Herrador (zherrador@isciii.es) ${ }^{3,4,5}$, J V San Martín' ${ }^{5,6}$, A Gherasim4, M Aguado ${ }^{6}$, A Romero-Maté6, L \\ Molina $^{6}$, P Aparicio $0^{4,5}$, A Benito 4,5 \\ 1. Network Biomedical Research Centre in Epidemiology and Public Health (CIBERESP in Spanish), Madrid, Spain \\ 2. Health Institute Carlos III (ISCIII), Madrid, Spain \\ 3. These authors contributed equally to this article \\ 4. National Centre for Tropical Medicine, ISCIII, Madrid, Spain \\ 5. Network Biomedical Research on Tropical Diseases (RICET in Spanish), Madrid, Spain \\ 6. Fuenlabrada University Hospital, Madrid, Spain
}

Citation style for this article:

Gomez-Barroso D, Herrador Z, San Martín JV, Gherasim A, Aguado M, Romero-Maté A, Molina L, Aparicio P, Benito A. Spatial distribution and cluster analysis of a leishmaniasis outbreak in the south-western Madrid region, Spain, September 2009 to April 2013. Euro Surveill. 2015;20(7):pii=21037. Available online: http://

www.eurosurveillance.org/ViewArticle.aspx?Articleld=21037

Since July 2009, there has been a community outbreak of leishmaniasis in south-west Madrid, Spain. The present study used the spatial distribution of cases to investigate the connection between the outbreak and a recently built peri-urban park. We included 157 cases of cutaneous (CL) and 90 cases of visceral (VL) leishmaniasis diagnosed at Fuenlabrada University Hospital between July 2009 and April 2013. CL and VL cases were geo-referenced and incidence rates by census tract were calculated. To identify high-risk areas, the spatial autocorrelation between individual cases was estimated. In a next step, areas where risk of disease was significantly increased were identified by cluster analysis. Higher incidence rates and the areas with highest intensity of $C L$ and $V L$ were located in the north-western part of the municipality. The most likely cluster of CL comprised three census tracks with relative risk $(R R)=11.5$ (95\% confidence interval (CI): 9.2-13.6). Two additional significant VL clusters were detected, the most likely one with $R R=9.2$ (95\% $\mathrm{Cl}$ : 7.3-11.1). In addition, we found one significant $\mathrm{VL}$ cluster in the immigrant population $(R R=12.8 ; 95 \% \mathrm{Cl}$ : 9.3-16.1). The spatial pattern of leishmaniasis transmission revealed a relation between the outbreak and the suspected risk area.

\section{Background}

Leishmaniasis is a parasitic disease caused by more than 20 protozoan species of the genus Leishmania. It is transmitted through the bite of female sandflies of the genera Phlebotomus (Old World) and Lutzomyia (New World). An ecological system in which a Leishmania species is maintained indefinitely is usually formed by one principal reservoir host, e.g. dogs for Leishmania infantum in both the Old and New Worlds [1]. Recent reports indicate that in Spain, other animals such as wild carnivores, rabbits and hares may play a role in the maintenance of the system, occasionally bringing the parasite from its enzootic focus into contact with humans $[2,3]$.

In Spain, leishmaniasis is endemic and both the visceral (VL) and the cutaneous (CL) forms are caused by $L$. infantum. Phlebotomine sandflies belonging to the subgenus Larroussius serve as vectors, while the dog is the main reservoir [4]. The real prevalence of leishmaniasis in Spain is unknown. Notification of leishmaniasis is not mandatory at national level (mandatory only in 12 of 17 regions) and there is no national leishmaniasis control programme [5]. Moreover, Leishmanias sp. cases are underascertained and underreported in Spain [6].

In the autonomous region of Madrid, notification of leishmaniasis has been mandatory since 1997 and is the most common zoonotic disease affecting infants and in patients with human immunodeficiency virus (HIV) infection [7,8]. Between 2000 and 2009, the annual incidence rate was around 0.5 per 100,000 population (between 12 and 25 leishmaniasis cases per year) [9]. During the last quarter of 2010, the case number increased fivefold. Subsequent research confirmed that an outbreak of leishmaniasis had been ongoing since July 2009 in the south-western area of the region of Madrid, with most cases occurring in the city of Fuenlabrada $[5,10]$.

Most of the $L$. infantum isolates obtained from patients in the outbreak area presented an uncommon strain: the combined genotype L-920 [2]. The initial hypothesis to explain this outbreak postulated risk areas for bites by Phlebotomus sandflies infected with this new strain, creating a temporospatial clustering of infected individuals. Because leishmaniasis was found in only 
Land use and population density, Fuenlabrada (Madrid), Spain, September 2009-April 2013

Land use

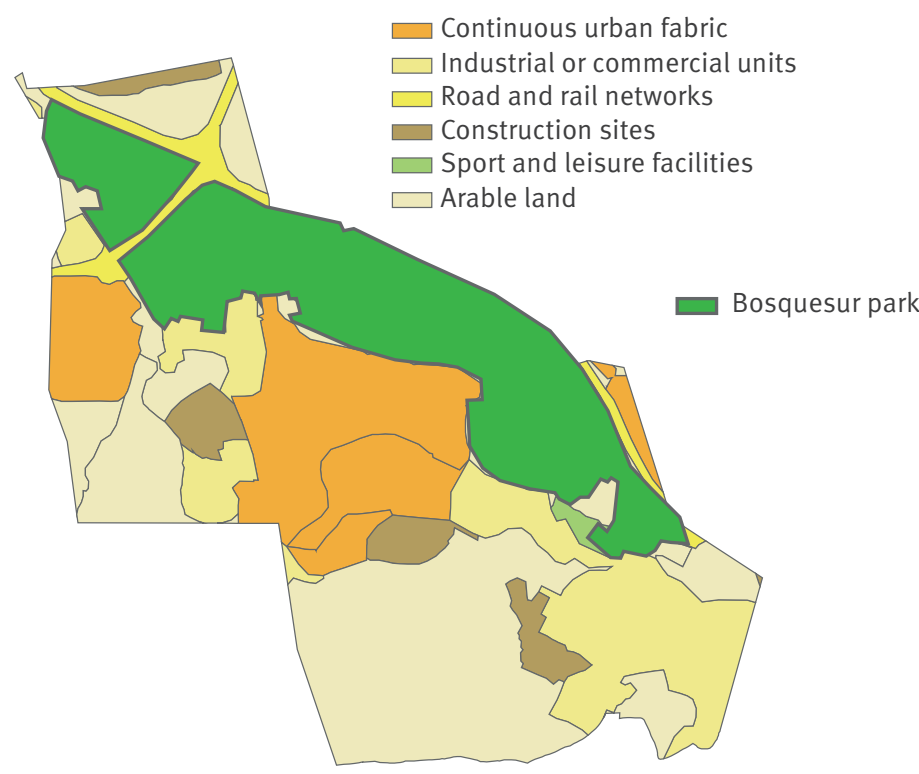

Source: Corine Land Cover 2006
Population density

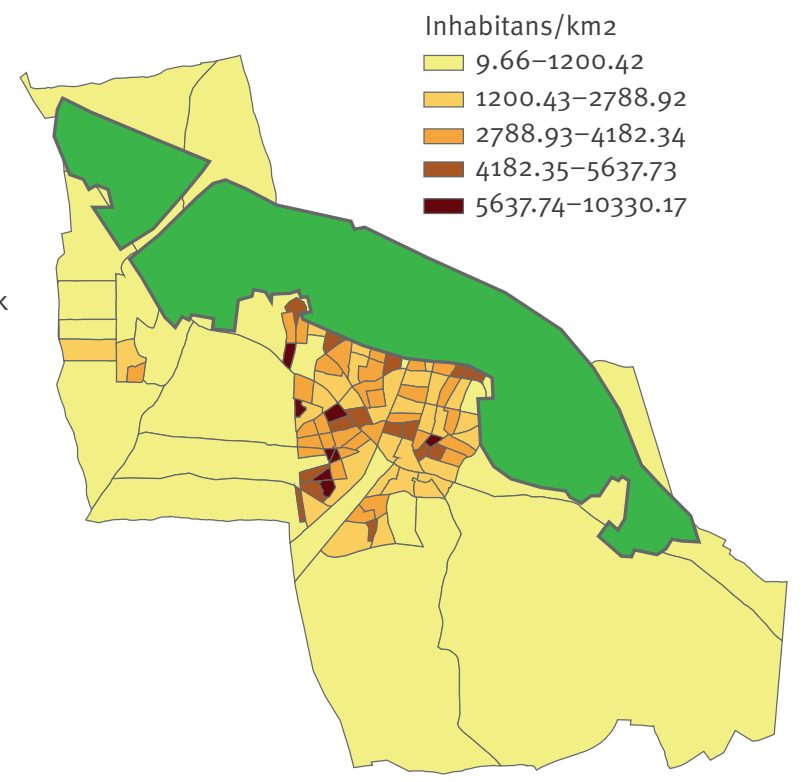

Source: Fuenlabrada Town Hall 2011

Maps were drafted using the free-licence source: Spanish National Institute of Geography. National Plan for Aerial Orthography (PNOA project). Available from: http://www.ign.es/ign/layoutIn/actividadesFotoTelePNOA.do [15].

$7 \%$ of the dogs examined in the outbreak area, other reservoirs were suspected and investigated. Around $30 \%$ of the hares studied were positive for Leishmania parasites [3,5], suggestive of a sylvatic transmission cycle possibly linked to a recently built park called Bosquesur, adjacent to the urban area of Fuenlabrada [11].

Spatial pattern analysis has been found to be useful to better understand disease transmission of parasitic diseases when there is a strong correlation between the spatial distribution of the disease and its hosts $[12,13]$. We aimed to assess the spatial distribution of $\mathrm{CL}$ and VL cases and the cluster occurrence within the city of Fuenlabrada (Madrid) as well as the distribution of the cases in relation with the park Bosquesur.

\section{Methods}

\section{Study area}

Fuenlabrada is a city and municipality located in the Madrid metropolitan area in central Spain. It is the fourth biggest town in the community of Madrid and is located in the south-west, ca $22 \mathrm{~km}$ from the capital. The climate is Mediterranean, with an estimated average annual rainfall of $450-500 \mathrm{~mm}$. The yearly mean maximum and minimum temperatures are $20.2^{\circ} \mathrm{C}$ and $7.6^{\circ} \mathrm{C}$, respectively. The mean altitude of the area is $664 \mathrm{~m}$ above sea level and the municipality is divided into 108 census track units. Figure 1 shows the municipality's land cover (based on data from the European
Environment Agency [14]) and population density at census track level to describe the study area.

\section{Cases}

CL and VL data from September 2009 to April 2013 were supplied by the Internal Medicine and Dermatology Departments of Fuenlabrada University Hospital. Diagnosis was confirmed by direct observation of the parasite in a skin biopsy specimen or by a positive polymerase chain reaction (PCR) as well as by isolation in Novy-MacNeal-Nicolle (NNN) culture. Further details on laboratory methods are provided elsewhere [2]. Data contained information on a number of clinical, epidemiological and demographic variables; those considered in this study were sex, age, address of residence, migrant status and date of symptom onset. Frequencies and percentages were used to summarise data. The differences were assessed by Student's t-test and chi-square test for continuous and categorical variables, respectively.

\section{Population}

The population data was obtained from the 2011 annual statistic published by the City of Fuenlabrada, stratified by sex and age, at census track level [15]. Fuenlabrada had an area of $39.1 \mathrm{~km}^{2}$ and an estimated population of 204,100 in 2011 , of whom $75.3 \%$ were in the age group of $16-64$ years and $15.4 \%$ were immigrants.

Spatial analysis

Geo-referencing of all VL and CL cases was carried out using Google Earth to obtain the geographical 
Monthly distribution of cutaneous $(n=157)$ and visceral $(n=90)$ leishmaniasis cases in Fuenlabrada (Madrid), Spain, September 2009-April 2013

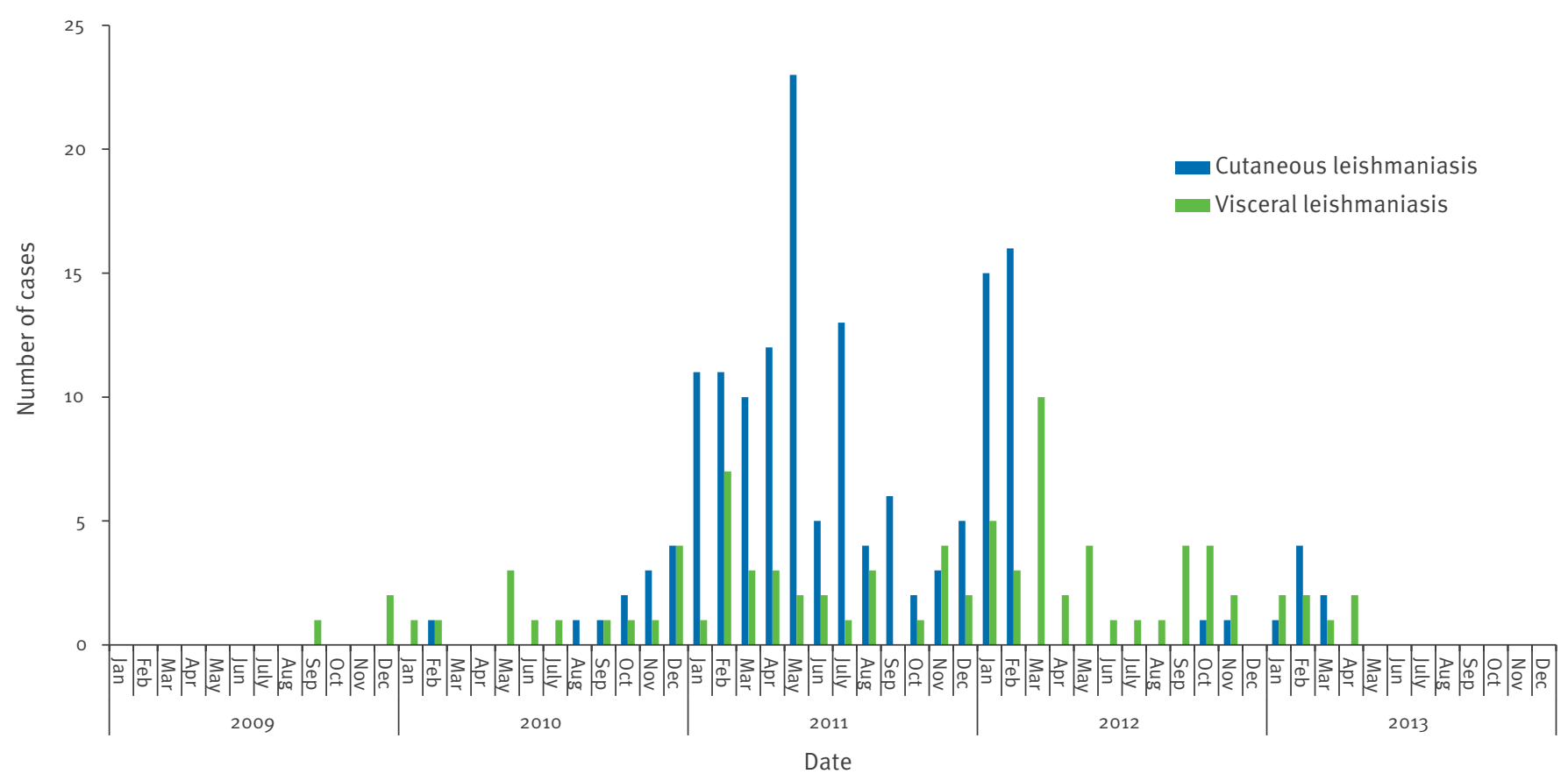

coordinates of patients' residences. In order to study the features of the territory, we obtained the map of Fuenlabrada by census track from the National Institute of Statistics (2011) [16] and downloaded images from the National Plan for Aerial Orthography (PNOA) project [17].

\section{Spatial distribution}

We calculated the incidence rates for CL and VL by census track adjusted by four age groups (0-14, 15-44, $45-64, \geq 65$ years) and by sex. We plotted the map with rates to understand the distribution of the disease at census track level. We calculated the local Moran's index in order to study the local indicator of spatial autocorrelation (LISA) between the rates. This index assesses local associations by comparing local averages to global average [18]. Its significance is estimated by generating a reference distribution using 999 random permutations. The LISA significance map includes the following categories: 'high-high' indicates clustering of high value rates (positive spatial autocorrelation), 'low-high' indicates that low value rates are adjacent to high value rates (negative spatial autocorrelation), 'low-low' indicates clustering of low value rates (positive spatial autocorrelation), 'high-low' indicates that high values are adjacent to low value rates (negative spatial autocorrelation), and 'not significant indicates that there is no spatial autocorrelation.

In order to understand the risk distribution, we estimated the spatial smoothing distribution of $C L$ and $V L$ by means of the kernel density function. This function is based on the quadratic kernel function described by Silverman [19]. This method is an interpolation and smoothing tool used to generalise the position of a point to an area. Kernel density estimation fits a curved surface over each case such that the surface is highest above the case and zero at a specified distance (the bandwidth) from the case.

To estimate the distance to the park Bosquesur, which was the main suspected risk area according to previous investigations $[3,11,20]$, we drew a polygon around this park. Distances to other landscape elements were also assessed. We created buffers with different distances: 500, 1,000 and 2,000 $\mathrm{m}$ around the park Bosquesur to measure the distances of the cases' addresses. Then, we calculated the average nearest neighbour index (ANNI) to calculate the distance between the location of each case and their nearest neighbour. This method was used as first approach to test whether or not the cases were clustering. If the average distance was below the average for a hypothetical random distribution, the distribution of the analysed characteristics was considered to be clustered. The index is expressed as the ratio of the observed distance divided by the expected distance. Thus, if the index is $<1$, the pattern exhibits clustering, while index of $>1$ indicates a trend towards dispersion. A significance level of $99 \%$ was chosen in the analysis.

\section{Cluster analysis}

Spatial clusters were analysed using the SaTScan spatial statistic estimator developed by Kulldorff [21]. To assess CL and VL spatial clusters in the entire population, and separately in the immigrant population, we 


\section{FIGURE 3}

Incidence rates of cutaneous ( $\mathrm{n}=157)$ and visceral $(\mathrm{n}=90)$ leishmaniasis, by census track, Fuenlabrada (Madrid), Spain, September 2009-April 2013

\section{A.Cutaneous leishmaniasis}

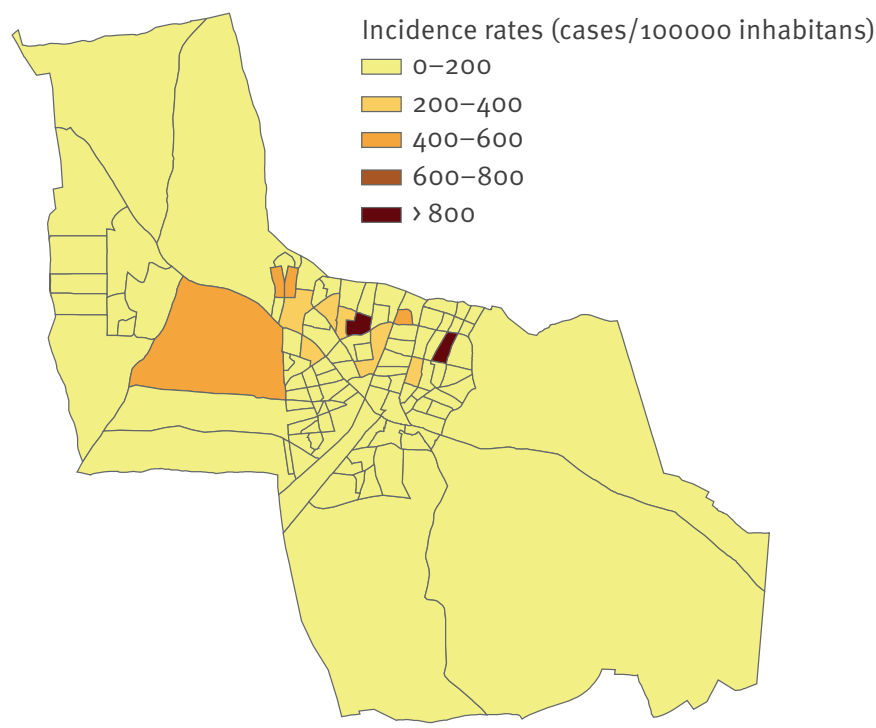

B. Visceral leishmaniasis

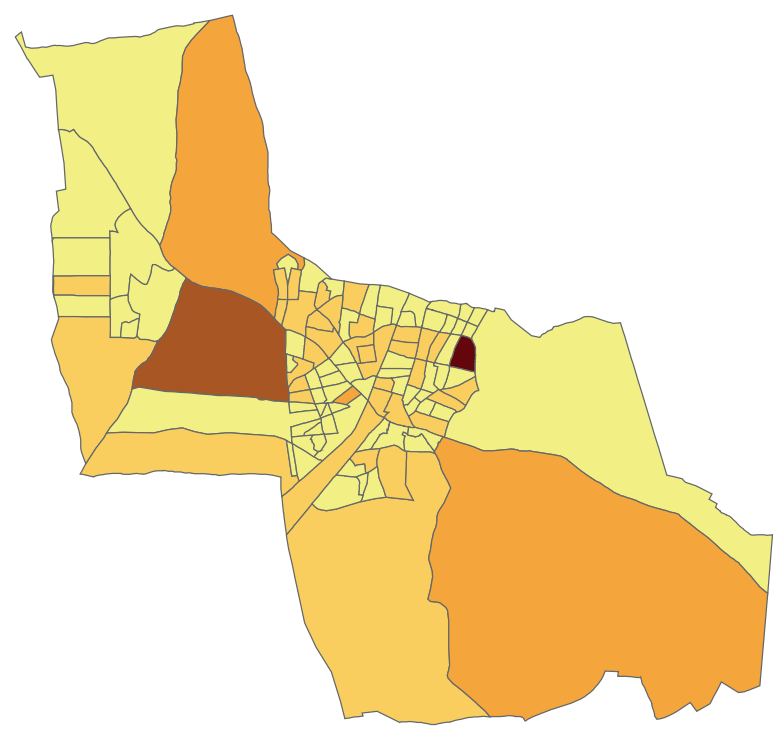

Maps were drafted using the free-licence source: Spanish National Institute of Geography. National Plan for Aerial Orthography (PNOA project). Available from: http://www.ign.es/ign/layoutIn/actividadesFotoTelePNOA.do [15].

\section{FIGURE 4}

Local indicator of spatial autocorrelation map for cutaneous $(n=157)$ and visceral $(n=90)$ leishmaniasis rates in Fuenlabrada (Madrid), Spain, September 2009-April 2013

\section{A.Cutaneous leishmaniasis}

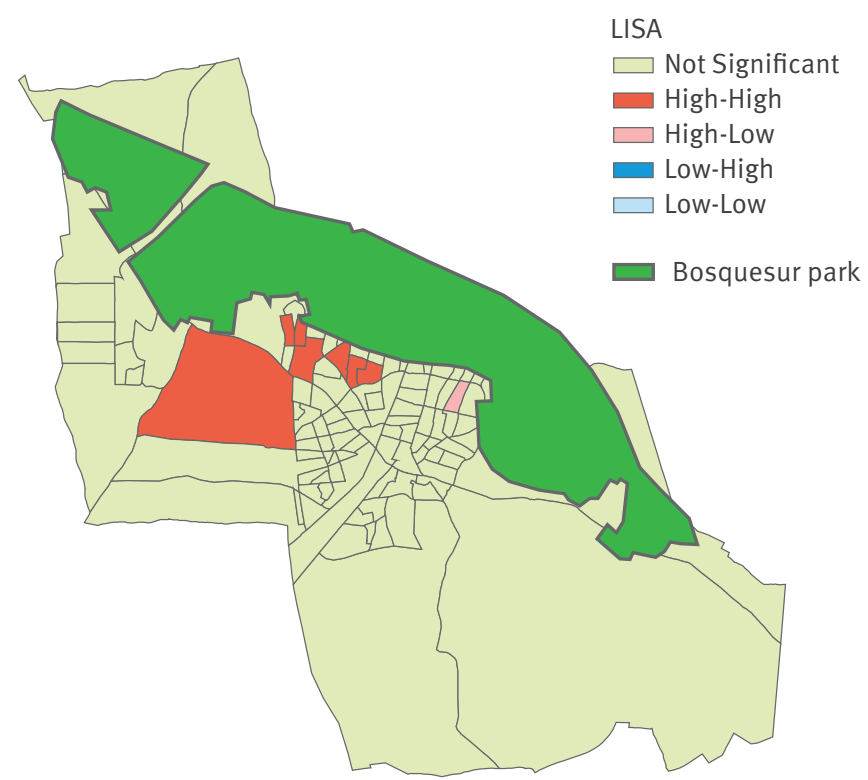

\section{B. Visceral leishmaniasis}

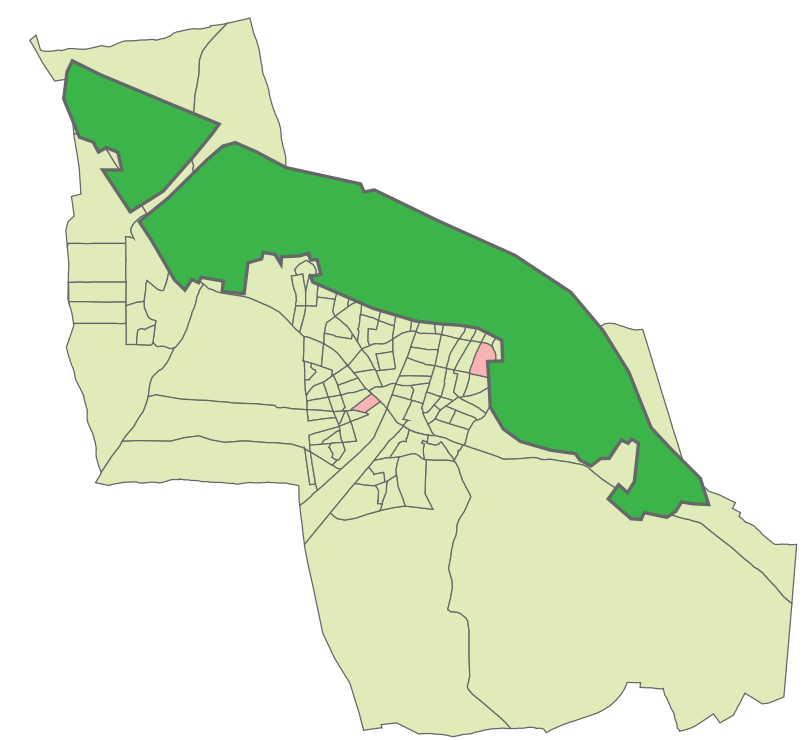

Maps were drafted using the free-licence source: Spanish National Institute of Geography. National Plan for Aerial Orthography (PNOA project). Available from: http://www.ign.es/ign/layoutln/actividadesFotoTelePNOA.do [15]. 
Kernel density for cutaneous $(n=157)$ and visceral $(n=90)$ leishmaniasis cases and buffer distances to the park Bosquesur, Fuenlabrada (Madrid), September 2009-April 2013

A.Cutaneous leishmaniasis

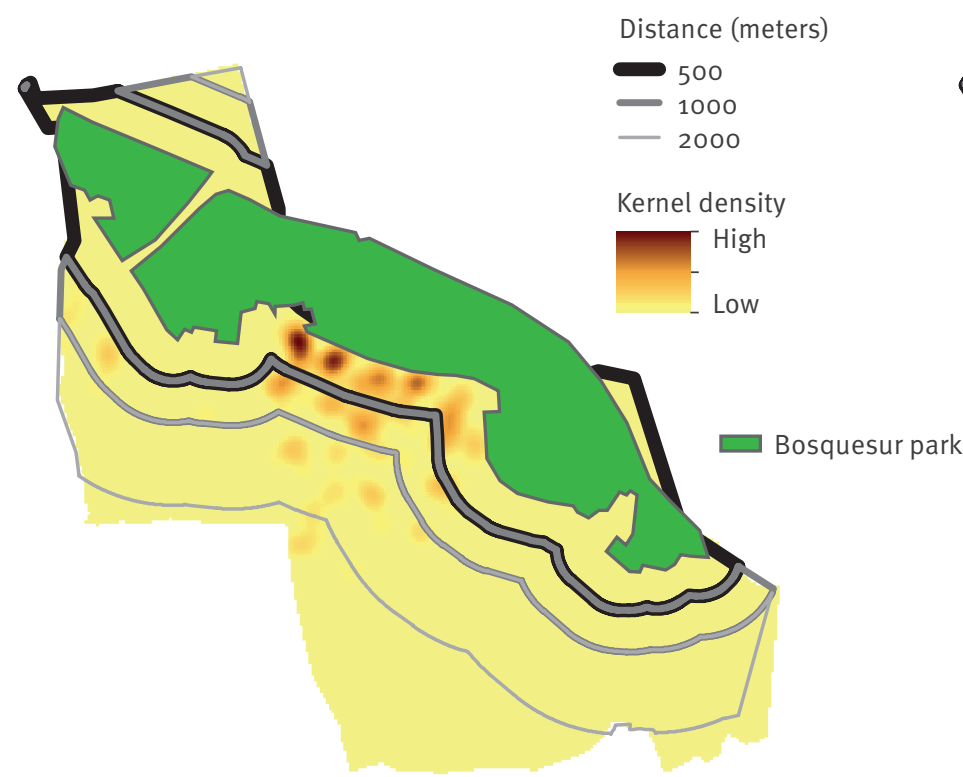

B. Visceral leishmaniasis

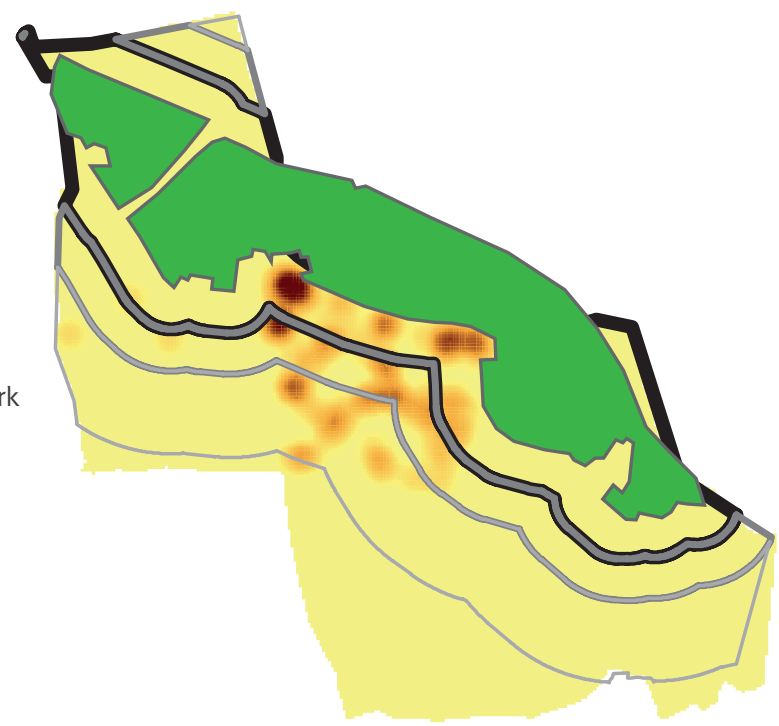

Maps were drafted using the free-licence source: Spanish National Institute of Geography. National Plan for Aerial Orthography (PNOA project). Available from: http://www.ign.es/ign/layoutIn/actividadesFotoTelePNOA.do [15].

used the scan statistic estimator to perform a purely spatial analysis, based on the assumption of a Poisson distribution. This method consists of creating a circular window which scans the entire study area. In our study we restricted the spatial window to a maximum radius of the average distance between cases (250 $\mathrm{m}$ ). The radius of the centroid varies continuously in size from zero to the specified upper limit, in our case 250 $\mathrm{m}$. The circle with maximum likelihood and containing more cases than expected is denominated the most likely cluster.

An increase in observed cases above the number expected was assessed using Monte Carlo test simulations (999 replications) with a 95\% confidence interval. For the spatial analysis, we used Arcgis version 10.0, free software GeoDa and SaTScan. Data analysis was performed using SPSS version 18.0.

\section{Results}

\section{Cases}

From September 2009 to April 2013, a total of 157 $\mathrm{CL}$ and $90 \mathrm{LV}$ cases were diagnosed at Fuenlabrada University Hospital. The distribution of CL cases over time (Figure 2) indicates that the first diagnosed $\mathrm{CL}$ cases appeared towards the end of 2010. CL cases climbed to a plateau during 2011, peaking twice, in May 2011 and January to February 2012. After the last maximum, CL cases dropped to zero for the rest of 2012, and rose again at the beginning of 2013. The first VL cases where detected already in 2009 . VL case numbers subsequently increased during 2011, reaching two peaks around the same time as the case numbers for $\mathrm{CL}$. However, in contrast to the CL cases, the VL cases continued to be diagnosed throughout 2012.

$52 \% \mathrm{CL}$ and $72 \% \mathrm{VL}$ cases were men ( $p<0.005$ ), with a median age of 48 and 46 years, respectively. The migration status was available for 246 of 247 cases. Eleven of $156(7.6 \%) C L$ cases and 35 of 90 (39\%) VL cases were immigrants $(p<0.001)$. Twenty-nine of the 46 immigrant cases were of Sub-Saharan origin (2/11 $\mathrm{CL}$ and $27 / 35 \mathrm{VL}$ ). No differences in sex and age distribution were found when comparing autochthonous and immigrant population.

\section{Spatial analysis}

\section{Spatial distribution}

The incidence rates of $C L$ and $L V$ in the different census tracks varied between zero and 1,003 and between zero and 613 cases per 100,000 population, respectively. Figure $3 \mathrm{~A}$ shows the distribution of $\mathrm{CL}$ rates. Higher rates of $C L$ (between 500 and 1,100 cases/100,000 population) were observed in three census track in the north of the municipality, while the highest rate for VL 


\section{TABLE 1}

Distance to the park Bosquesur and distribution of cutaneous $(n=157)$ and visceral $(n=90)$ leishmaniasis cases, Fuenlabrada (Madrid), Spain, September 2009April 2013

\begin{tabular}{|l|c|c|c|c|}
\hline \multirow{2}{*}{ Distance } & \multicolumn{2}{|c|}{$\begin{array}{c}\text { Cutaneous } \\
\text { leishmaniasis }\end{array}$} & \multicolumn{2}{c|}{$\begin{array}{c}\text { Visceral } \\
\text { leishmaniasis }\end{array}$} \\
\cline { 2 - 5 } & Cases & $\%$ & Cases & $\%$ \\
\hline$<500 \mathrm{~m}$ & 82 & 52.2 & 37 & 41.1 \\
\hline $500-1,000 \mathrm{~m}$ & 40 & 25.5 & 28 & 31.1 \\
\hline $1,000-2,000 \mathrm{~m}$ & 20 & 12.7 & 21 & 23.3 \\
\hline$>2,000 \mathrm{~m}$ & 15 & 9.6 & 4 & 4.4 \\
\hline Total & 157 & 100 & 90 & 100 \\
\hline
\end{tabular}

was found in a different northern census track (Figure 3B).

The LISA for CL and VL rates are shown in Figure 4. Significant clusters of high values for $C L$ and $V L$ were detected: a CL hotspot $(p<0.005)$ in a census track located in the north-west of the municipality, and two significant VL hotspots $(p<0.005)$ in two census tracks with high values adjacent to census tracks with low value rates.

The average distance among the cases (bandwidth) was $250 \mathrm{~m}$. Following spatial smoothing, areas with high intensity for $C L$ were identified in the north of the city, close to the park Bosquesur (Figure $5 \mathrm{~A}$ ). The distribution of the $\mathrm{VL}$ cases is shown in Figure $5 \mathrm{~B}$; high intensity areas were located in the northern part of the municipality.

Table 1 summarises the cases distribution and distance to the park. We observed a decreasing trend in $\mathrm{CL}$ and $\mathrm{VL}$ occurrence in relation to the distance to the park. Up to $75 \%$ of $\mathrm{CL}$ cases and $70 \%$ of VL cases lived in places less than $1 \mathrm{~km}$ from this suspected risk area.

The ANNI was 0.505 (p<0.001) for $C L$ and 0.582 ( $p<0.001$ ) for VL throughout the study area. Both for CL and VL, the pattern exhibited clustering. The observed average distances were 98 and $270 \mathrm{~m}$ and the expected average distances were 193 and $463 \mathrm{~m}$ for CL and VL, respectively.

\section{Cluster analysis}

Four significant $C L$ clusters were identified through spatial cluster analysis ( $p<0.001$, Figure $6 A)$. The most likely cluster comprised three census tracks in which 24 cases were diagnosed during the study period, while the number of expected cases was 2.46 (relative risk $(R R)=11.50$ and $p<0.005)$. Other secondary clusters were located in the north of the municipality.
The VL spatial cluster analysis detected two significant clusters ( $p<0.001$, Figure 6B; Table 2). The most likely cluster comprised one census track with eight cases and an expected number of cases of 0.95 . The RR was $9.15(p<0.005)$. The other secondary cluster was located in the north-eastern part of the municipality.

When we analysed the data according to the migrant status, we found one significant cluster for VL in the immigrant population, with four observed cases, 0.35 expected cases and a RR of 12.75 ( $p<0.005$ ) (Figure $6 \mathrm{C})$. This cluster included one census track located in the north of the municipality, different from the one detected for VL in overall population. No significant cluster of $\mathrm{CL}$ was identified through spatial cluster analysis in the immigrant population.

\section{Discussion}

Our study revealed the spatial characteristics of human $\mathrm{CL}$ and VL during an outbreak in Fuenlabrada (Madrid) using geographic information system (GIS) tools and spatial statistical analysis. Similar approaches have been used in Spain to investigate the spatial distribution of the sandfly vector and canine leishmaniasis $[4,22]$. However, to our knowledge this is the first attempt to implement spatial techniques to assess the distribution and cluster occurrence of human CL and VL cases in an outbreak in Europe.

We have described the evolution of the VL and $C L$ cases in Fuenlabrada separately, as analysing them together may have resulted in misinterpretation. VL was more common in men than in women, while no sex differences were found for $\mathrm{CL}$. This seems to be concordant with findings from previous epidemiological studies indicating that VL occurs more frequently among adult men $[20,23]$. Although it has been hypothesised that sex hormones play a role in the modulation of immunity against leishmaniasis [24], the explanation for this trend still remains uncertain.

In our research, the census tracks with the highest incidence of $\mathrm{CL}$ were different from the ones with highest incidence of VL. It is difficult to determine whether the different distribution of $\mathrm{CL}$ and $\mathrm{VL}$ cases determined by disease onset, vector distribution, disease transmission pattern and/or presence of the host. Leishmaniasis is known to be a diverse and complex disease [1], therefore further studies may be needed to investigate this particular finding.

Although the spatial distribution of $C L$ and VL leishmaniasis did not overlap perfectly in space, both were spatially clustered along the border of a park. Risk associated with other landscape elements within the municipality were analysed without significant results. Leishmaniasis is one of the main parasitic diseases of the world for which the transmission profile includes landscape elements and environment [25]. In our research, all spatial methods deployed showed that the northern peripheral census tracks were the most 


\section{FIGURE 6}

Significant clusters of cutaneous ( $n=61$ cases) and visceral ( $n=13$ cases) leishmaniasis in the overall and immigrant population, Fuenlabrada (Madrid), Spain, September 2009-April 2013

\section{A.Cutaneous leishmaniasis}

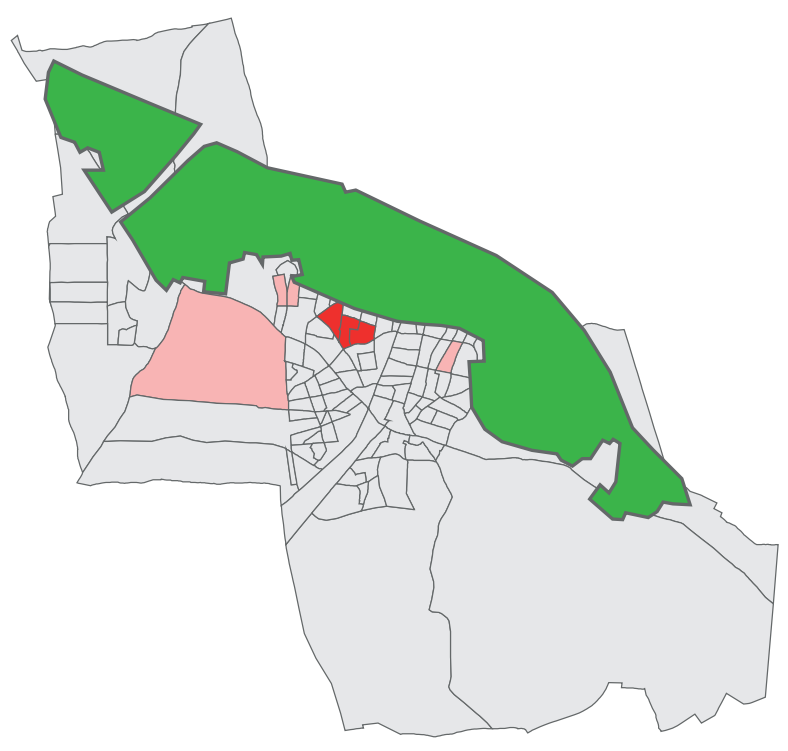

\section{Clusters $p<0.05$}

Most likely cluster

$\square$ Secondary clusters

Bosquesur park

\section{B. Visceral leishmaniasis}

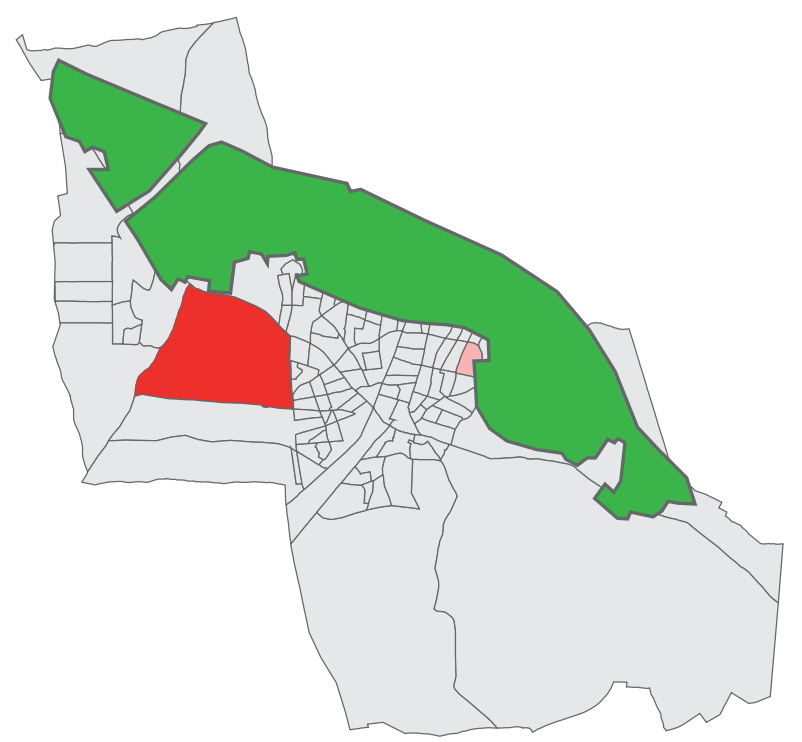

C. Visceral leishmaniasis immigrants

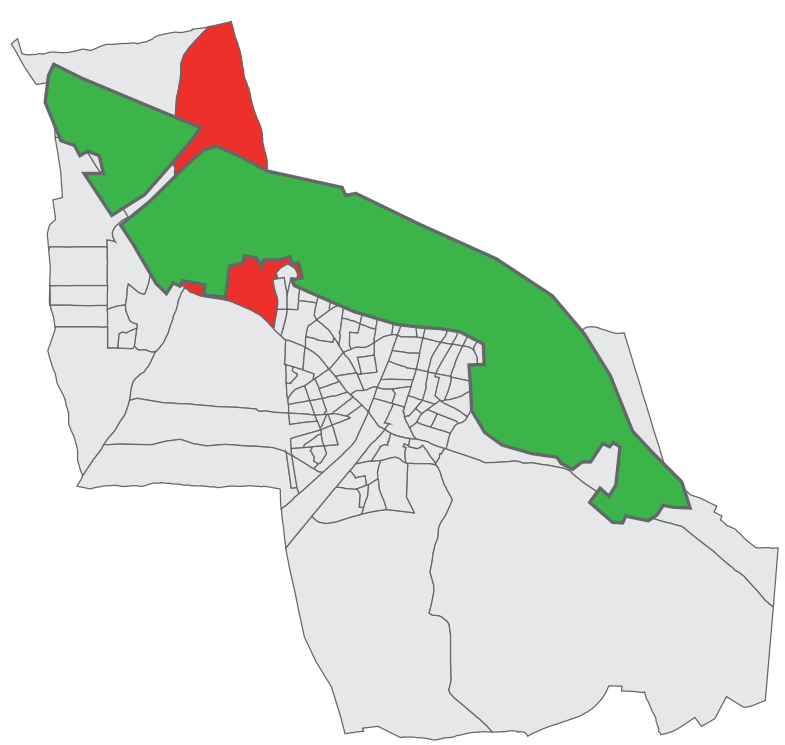

Maps were drafted using the free-licence source: Spanish National Institute of Geography. National Plan for Aerial Orthography (PNOA project). Available from: http://www.ign.es/ign/layoutIn/actividadesFotoTelePNOA.do [15]. 
Significant clusters of cutaneous ( $\mathrm{n}=61$ cases) and visceral ( $\mathrm{n}=13$ cases) leishmaniasis, Fuenlabrada (Madrid), Spain, September 2009-April 2013

\begin{tabular}{|c|c|c|c|c|c|c|c|}
\hline & Cluster & $\begin{array}{c}\text { Number of } \\
\text { census tracks }\end{array}$ & Observed & Expected & RR & LLR & $p$ value \\
\hline \multirow{4}{*}{ Cutaneous leishmaniasis } & 1 & 3 & 24 & 2.5 & 11.5 & 34.9 & 0.000 \\
\hline & 2 & 1 & 11 & 1.0 & 11.9 & 16.8 & 0.000 \\
\hline & 3 & 2 & 16 & 3.4 & 5.2 & 12.8 & 0.000 \\
\hline & 4 & 1 & 10 & 1.5 & 7.09 & 10.6 & 0.000 \\
\hline \multirow{2}{*}{ Visceral leishmaniasis } & 1 & 1 & 8 & 1.0 & 9.2 & 10.3 & 0.000 \\
\hline & 2 & 1 & 5 & 0.5 & 11.4 & 7.5 & 0.001 \\
\hline VL immigrants & 1 & 1 & 4 & 0.4 & 12.8 & 6.3 & 0.002 \\
\hline
\end{tabular}

LRR: log-likelihood ratio; RR: relative risk; VL: visceral leishmaniasis.

heavily affected. Moreover, CL and VL incidence rates and the distance to the park Bosquesur were spatially correlated. Finally, the cluster analysis also showed that the most likely CL and VL clusters were close to this park.

Our results were in accordance with previous research that emphasises that this disease can be associated with urbanisation close to vegetation areas [23,26,27]. Worldwide, leishmaniasis outbreaks have been related to human activities close to or within forested areas: road construction, building of dams, irrigation schemes and horticulture development, and establishment of new residential colonies lead to intrusion into the sylvatic cycle of the disease $[27,28]$. The park Bosquesur is a man-made natural area, located between the towns of Alcorcón, Leganés, Fuenlabrada, Getafe and Pinto. During the outbreak period, leishmaniasis cases were reported from these five towns [10]. Adjacent to this newly planted area, public construction work was carried out on one of the main roads $(M-407)$ to Fuenlabrada in 2009-10. All these recent changes at peri-urban level may have altered the ecology of this area and the transmission dynamics of leishmaniasis.

The sum of observed cases in the four significant clusters of CL was 61 (39\% of the total $157 \mathrm{CL}$ cases included in the analysis), while the percentage of VL cases included in the significant clusters was even lower, $14 \%(n=13)$ of the $90 \mathrm{VL}$ cases. This difference in case clustering can also be observed in the epidemiological curve (Figure 2), although we cannot draw conclusions in this regard as we did not carry out a temporospatial analysis. Other exposure pathways are also plausible. As shown by de Almeida et al., the pattern of leishmaniasis is not static and the disease may spread from one area of a municipality to another [29]. On the other hand, the use of a patient's home residence as a marker of the place of infection may not be accurate because contact between host and vector can have occurred outside the home.
The park has several recreational areas with footpaths and bicycle trails [30]. Social networks, recreational activities and other interactions between human settlements and the peri-urban natural environment may play a role in the distribution of the disease in this context $[26,28]$. Nevertheless, these establishments are attended mostly during daytime. First appearance of active $P$. perniciosus females occurs at sunset and the density peak is usually reached around 23:00-24:00 $[5,11]$. Therefore, the highest probability of transmission may be not associated with the presence of individuals inside the park, but rather in homes or outdoor places close to, but outside the park.

According to Arce et al., patients were asked during the outbreak investigation about recreational habits, but neither particular areas nor classic environmental risk factors were identified [10]. It should be noticed that only cases were assessed during the official investigation. We believe that the outbreak investigation would have benefited from a control group in order to evaluate exposures and risk factors.

A high percentage of VL cases (39\%) were immigrants and we identified a cluster of $V L$ in this particular group. This cluster did not overlap with the VL cluster detected in overall population. We also carried out the analysis in the non-immigrant population only (data not shown) and did not find any relevant difference compared to the analysis on entire population. According to official data from the local authorities, $15.4 \%$ of the Fuenlabrada population in 2011 were immigrants, of which $14.9 \%$ are from Sub-Saharan Africa [15]. The percentage of immigrants in the study area was similar to that of other urban areas in Spain [31]. Several factors could have been responsible for the high percentage of VL in immigrants: migration of non-immune people from areas where $L$. infantum is not endemic $[1,32]$, differences in host immune responses [33], and differences in living habits and/or health-seeking behaviour. These factors should be explored in further investigations. 
Our study has several limitations. One relates to the long incubation period of the disease, rendering determining and interpreting the information related to transmission site difficult. Control measures may have affected the spatial distribution of cases. We are aware of disinfection activities undertaken since 2011; although no information on the targeted sites is publically available, we cannot discard their impact on the case distribution.

We chose Kulldorff's method for the spacial cluster analysis because it has several advantages [34]: it adjusts for population density and confounding variables (e.g. age and sex); there is no pre-selection bias since the clusters are selected without prior hypothesis on their location, size or time period; the statistical test takes into account multiple testing and delivers a single $p$ value; if a cluster is detected, its location is specified.

In a molecular typing study, Chicharro et al. found that the outbreak was not caused by a single parasite strain, as four combined genotypes were found. At Fuenlabrada Hospital, the ITS-LOMBARDI type was isolated from all serotyped cases. This $L$. infantum ITS type has been present in this region since at least 1992 [2]. A high density of $P$. perniciosus has also been observed in the park [10]. In previous research carried out in central Spain, a correlation was found between vector density and cases living in areas between villages or at the limits of a village [22]. Future entomological and molecular typing studies could benefit from our results, as a combined methodology could allow more precise conclusions regarding the transmission patterns.

\section{Conclusion}

Although our study design did not allow establishing causal associations, the methodology can be considered useful in generating hypotheses during an outbreak investigation. Future work should examine the role of vector density, seroprevalence of Leishmania in canine and other possible reservoirs, climate variability, socio-economic conditions, land use and changes made by humans to the habitat over a longer time span in the study area. This will allow building accurate risk maps and targeting prevention and treatment interventions in these high-risk areas in a timely manner.

\section{Acknowledgements}

The authors gratefully acknowledge the financial support of the Health Institute Carlos III via the Tropical Diseases Research Network (RICET). The funders had no role in study design, data collection and analysis, decision to publish, or preparation of the manuscript.

\section{Conflict of interest}

None declared.
Authors' contributions

Diana Gomez-Barroso - writing of the manuscript, epidemiological data analysis and interpretation of the study. Zaida Herrador - writing of the manuscript, epidemiological data analysis and interpretation of the study. Juan Victor San Martin - interpretation of the study and contributed to the revision of the draft manuscript. Alin Gherasim - epidemiological data analysis, interpretation of the study and contributed to the revision of the draft manuscript. Marta Aguado - contributed to the revision of the draft manuscript. Alberto Romero-Maté - contributed to the revision of the draft manuscript. Laura Molina - contributed to the revision of the draft manuscript - Pilar Aparicio - contributed to the revision of the draft manuscript; and Agustín Benito - interpretation of the study and contributed to the revision of the draft manuscript.

\section{References}

1. World Health Organization (WHO). Control of the leishmaniases. Report of a meeting of the WHO Expert Committee on the Control of Leishmaniases, Geneva, 22-26 March 2010. WHO Tech Rep Ser, no. (2).Available from: http:// whqlibdoc.who.int/trs/WHO_TRS_949_eng.pdf

2. Chicharro C, Llanes-Acevedo IP, García E, Nieto J, Moreno J, Cruz I. Molecular typing of Leishmania infantum isolates from a leishmaniasis outbreak in Madrid, Spain, 2009 to 2012. Euro Surveill. 2013;18(30):20545. http://dx.doi.org/10.2807/15607917.ES2013.18.30.20545 PMID:23929179

3. Molina R, Jiménez MI, Cruz I, Iriso A, Martín-Martín I, Sevillano 0 , et al. The hare (Lepus granatensis) as potential sylvatic reservoir of Leishmania infantum in Spain. Vet Parasitol. 2012;190(1-2):268-71. http://dx.doi.org/10.1016/j. vetpar.2012.05.006 PMID:22677135

4. Galvez R, Descalzo MA, Guerrero I, Miro G, Molina R. Mapping the current distribution and predicted spread of the leishmaniosis sand fly vector in the madrid region (Spain) based on environmental variables and expected climate change. Vector Borne Zoonotic Dis. 2011;11(3):799-806. http:// dx.doi.org/10.1089/vbz.2010.0109 PMID:21417927

5. Centro de Coordinación de Alertas y Emergencias sanitarias (CCAES), Ministerio de Sanidad, Politica Social e Igualdad (MSPSI). Evaluación del riesgo de transmisión de Leishmania infantum en España. [Risk assessment of Leishmania infantum transmission in Spain]. Madrid: MSPSI; 2012. Spanish. Available from: http://www.msssi.gob.es/profesionales/ saludPublica/ccayes/analisisituacion/doc/leishmania.pdf

6. Garrote JI, Gutiérrez MP, Izquierdo RL, Dueñas MAI, Zarzosa $P, C a n ̃ a v a t e ~ C$, et al. Seroepidemiologic study of Leishmania infantum infection in Castilla-Leon, Spain. Am J Trop Med Hyg. 2004;71(2):403-6. PMID:15516634

7. Alvar J, Aparicio P, Aseffa A, Den Boer M, Cañavate C, Dedet J-P, et al. The relationship between leishmaniasis and AIDS: the second 10 years. Clin Microbiol Rev. 2008;21(4):334-59. http:// dx.doi.org/10.1128/CMR.00061-07 PMID:18400800

8. Manual de notificación del sistema de enfermedades de declaración obligatoria. Documentos técnicos de salud pública no. 69. [Manual of the notification system for notifiable diseases. Public health technical papers no. 69]. Madrid: Public Health Institute Community of Madrid; 2006. Spanish. Available from: http://www.madrid.org/cs/Satellite?c=CM_ Publicaciones FA\&cid $=1142284809709 \&$ idConsejeria $=110926$ $6187266 \&$ idListConsj $=1109265444710$ \&idOrganismo $=1142439$ 320383 \&language $=$ es\&pagename $=$ ComunidadMadrid $\% 2$ FEstr uctura \&sm $=1109266101003$

9. Morbilidad por enfermedades de declaración obligatoria. Comunidad de Madrid. Año 2010. [Morbidity of compulsory notifiable diseases. Community of Madrid. Year 2010]. Boletín epidemiológico de la Comunidad de Madrid. 2011;17(11). Spanish. Available from: http://www.madrid.org/cs/Satellite?b lobcol=urldata\&blobheader=application $\% 2$ Fpdf\&blobheadern ame $1=$ Content-Disposition\&blobheadervalue $1=$ filename $\% 3 D N$ oviembre2011.pdf\&blobkey=id\&blobtable=MungoBlobs\&blob where $=1310910631705$ \&ssbinary $=$ true

10. Arce A, Estirado A, Ordobas M, Sevilla S, García N, Moratilla $\mathrm{L}$, et al. Re-emergence of leishmaniasis in Spain: community outbreak in Madrid, Spain, 2009 to 2012. Euro Surveill. 2013;18(30):20546. http://dx.doi.org/10.2807/1560-7917. ES2013.18.30.20546 PMID:23929177

11. Jiménez M, González E, Iriso A, Marco E, Alegret A, Fúster F, et al. Detection of Leishmania infantum and identification of blood meals in Phlebotomus perniciosus from a focus 
of human leishmaniasis in Madrid, Spain. Parasitol Res. 2013;112(3):2453-9. http://dx.doi.org/10.1007/s00436-0133406-3 PMID:23535889

12. Kulldorff M, Heffernan R, Hartman J, Assunção R, Mostashari F. A space-time permutation scan statistic for disease outbreak detection. PLoS Med. 2005;2(6):e59. http://dx.doi.org/10.1371/ journal.pmed.0020059 PMID:15719066

13. Mott KE, Nuttall I, Desjeux P, Cattand P. New geographical approaches to control of some parasitic zoonoses. Bull World Health Organ. 1995;73(4):247-57. PMID:7743598

14. European Environment Agency (EEA). Corine Land Cover 2006 raster data. Copenhagen: EEA. [Accessed: 28 Apr 2014]. Available from: http://www.eea.europa.eu/data-and-maps/ data/corine-land-cover-2006-raster

15. Población de Fuenlabrada, 2011. [Population of Fuenlabrada, 2011]. Fuenlabrada: City of Fuenlabrada. [Accessed 9 September 2013]. Spanish. Available from: http://aytofuenlabrada.es/index.do? $M P=3 \& M S=27 \& M N=2$

16. National Statistics Institute. Population and Housing Census 2011. Madrid: Instituto Nacional de Estadística. [Accessed: 5 October 2013]. Available from: http://www.ine.es/en/ censos2011_datos/cen11_datos_resultados_seccen_en.htm

17. Spanish National Institute of Geography. Plan Nacional de Ortofotografía Aérea. [National Plan for Aerial Orthography]. Madrid: Instituto Geográfico Nacional. [Accessed; DATE]. Spanish. Available from: http://www.ign.es/ign/layoutln/ actividadesFotoTelePNOA.do

18. Anselin L. Locals indicator of spatial association-LISA. Geogr Anal. 1995;27(4):93-115.

19. Silverman BW. Density Estimation for Statistics and Data Analysis. London: Chapman and Hall/CRC; 1998.

20. Suárez Rodríguez B, Isidoro Fernández B, Santos Sanz S, Sierra Moros MJ, Molina Moreno R, Astray Mochales J, et al. [Review of the current situation and the risk factors of Leishmania infantum in Spain]. Rev Esp Salud Publica. 2012;86(8):555-64. PMID:23325131

21. Kulldorff M. A spatial scan statistic. Commun Stat Theory Methods. 1997;26(8):1481-96. http://dx.doi. org/10.1080/03610929708831995

22. Gálvez R, Descalzo MA, Miró G, Jiménez MI, Martín O, Dos Santos-Brandao F, et al. Seasonal trends and spatial relations between environmental/meteorological factors and leishmaniosis sand fly vector abundances in Central Spain. Acta Trop. 2010;115(1-2):95-102. http://dx.doi.org/10.1016/j. actatropica.2010.02.009 PMID:20171154

23. Werneck GL, Costa CHN, Walker AM, David JR, Wand M, Maguire JH. The urban spread of visceral leishmaniasis: clues from spatial analysis. Epidemiology. 2002;13(6):3647. http://dx.doi.org/10.1097/00001648-200205000-00020 PMID:11964941

24. Snider H, Lezama-Davila C, Alexander J, Satoskar AR. Sex hormones and modulation of immunity against leishmaniasis. Neuroimmunomodulation. 2009;16(4):106-13. http://dx.doi. org/10.1159/000180265 PMID:19212130

25. Valderrama-Ardila C, Alexander N, Ferro C, Cadena H, Marín D, Holford TR, et al. Environmental risk factors for the incidence of American cutaneous leishmaniasis in a subAndean zone of Colombia (Chaparral, Tolima). Am J Trop Med Hyg. 2010;82(4):243-50. http://dx.doi.org/10.4269/ ajtmh.2010.09-0218 PMID:20134000

26. Gil JF, Nasser JR, Cajal SP, Juarez M, Acosta N, Cimino RO, et al. Urban transmission of American cutaneous leishmaniasis in Argentina: spatial analysis study. Am J Trop Med Hyg. 2010;82(6):433-40. http://dx.doi.org/10.4269/ ajtmh.2010.09-0113 PMID:20207869

27. Ready PD. Leishmaniasis emergence and climate change. Rev Sci Tech. 2008 Aug;27(4):399-412. PMID:18819668

28. Campbell-Lendrum D, Dujardin JP, Martinez E, Feliciangeli MD, Perez JE, Silans LN, et al. Domestic and peridomestic transmission of American cutaneous leishmaniasis: changing epidemiological patterns present new control opportunities. Mem Inst Oswaldo Cruz. 2001;96(4):159-62. http://dx.doi. org/10.1590/So074-02762001000200004 PMID:11285490

29. de Almeida AS, Medronho R de A, Werneck GL. Identification of risk areas for visceral leishmaniasis in Teresina, Piaui State, Brazil. Am J Trop Med Hyg. 2011;84(9):681-7. http://dx.doi. org/10.4269/ajtmh.2011.10-0325 PMID:21540375

30. La Red de Centros de la Consejería de Medio Ambiente y Ordenación del Territorio. [Network of Centers from the Regional Ministry of Environment and Spatial Planning]. Madrid: Community of Madrid. [Accessed: 10 Jan 2014]. Spanish. Available from: http://www.madrid.org/cs/ Satellite?c=CM_Actuaciones_FA\&cid=1142314660051\&idTema $=1109265603340 \&$ language $=e s \&$ pagename $=$ ComunidadMadri $d \% 2$ FEstructura\&pv $=1142343852186 \&$ segmento $=1$
31. National Statistics Institute. Encuesta Nacional de Inmigrantes 2007. [National Immigrant Survey 2007]. Madrid: Instituto Nacional de Estadística. [Accessed: 10 Jan 2014]. Spanish. Available from: http://www.ine.es/jaxi/menu.do?type=pcaxis \&path $=\% 2 \mathrm{Ft} 20 \% 2 \mathrm{Fp} 319$ \& file $=$ inebase $\& \mathrm{~L}=0$

32. Pavli A, Maltezou HC. Leishmaniasis, an emerging infection in travelers. Int J Infect Dis. 2010;14(10):e1032-9. http://dx.doi. org/10.1016/j.ijid.2010.06.019 PMID:20952234

33. Maache M, Azzouz S, Diaz de la Guardia R, Alvarez P, Gil $\mathrm{R}$, de Pablos LM, et al. Host humoral immune response to Leishmania lipid-binding protein. Parasite Immunol. 2005;27(8):227-34. http://dx.doi.org/10.1111/j.13653024.2005.00773.x PMID:16048642

34. Gomez-Barroso D, Varela C, Ramis R, Del Barrio JL, Simón F. Space-time pattern of hepatitis A in Spain, 1997-2007. Epidemiol Infect. 2012;140(6):407-16. http://dx.doi. org/10.1017/So950268811000811 PMID:21676358 